\title{
Modeling and Prediction of Wear for Gears in Plastic Materials and Their Composites
}

\author{
N. Agbetossou ${ }^{1}$, A. Afio ${ }^{1}$, K. Attipou ${ }^{1}$ \\ ${ }^{1}$ Département De Génie Mécanique, \\ Ecole Nationale Supérieure D'ingénieurs, Université De \\ Lomé, B.P. 1515 Lomé, Togo

\section{Koffi ${ }^{2}$} \\ ${ }^{2}$ Centre De Recherche En Matériaux Ligno Cellulosiques, \\ Département De Génie Mécanique, \\ Ecole D'ingénierie, Université Du Québec A Trois- \\ Rivières, Cp 500, Trois-Rivières, Québec, G9a 5h7, \\ Canada
}

\author{
K. A. Kassegne ${ }^{3}$, \\ ${ }^{3}$ Maître De Conférences, \\ Département De Génie Mécanique, \\ Ecole Nationale Supérieure D'ingénieurs, \\ Université De Lomé, B.P. 1515 \\ S. Tiem ${ }^{4}$ \\ ${ }^{4}$ Professeur Titulaire, \\ Département De Génie Mécanique, \\ Ecole Nationale Supérieure D'ingénieurs, \\ Université De Lomé, B.P. 1515
}

\begin{abstract}
This work deals with the modeling and prediction of the wear of plastic gears and their composites. The literature shows that the worn shape of gear teeth for gears in plastic materials and their composites differs from that of their metal gear counterparts. This makes existing models of wear prediction in metallic gears unsuitable for gears made of plastic materials and their composites.

Two models based on Archard's law, namely the adapted Flodin model and a new model with an exponential coefficient of wear, are developed in this study. Simulations on acetal gears were implemented using models developed with Matlab code and the numerical results obtained are presented and discussed.

The results of the two wear models effectively give the worn shape of the profiles in accordance with that obtained by the experimental tests of Düzcükoğlu [11].

The new wear model compared to the Flodin model presents a simplicity in determining its exponential wear coefficient $\lambda$. The exponential wear coefficient $\lambda$ is more stable face the variations of the operating parameters than the wear coefficient $k$ of the Flodin model.

Using the results of experimental tests carried out on acetal gears by K. Mao [9], a validation method is proposed and shows a good agreement between the experimental results and those of our new model
\end{abstract} Keys words: plastic gear, wear, modeling, exponential wear coefficient, Matlab.

\section{I- INTRODUCTION}

Plastic gears and their composites have many advantages and they will continue to beneficially replace metal gears in many applications in all areas. Above all, today that the family of plastic materials and their composites is growing with the development of new eco-plastics and their natural fiber composites as an alternative for sustainable development, it is therefore essential to continue research in the field of plastic gears and their composites in order to overcome the problems that still hinder their use.

In gear transmissions, there is a relative slip between the two profiles in contact due to the very kinematics of the gear transmission mechanism. This slip associated with the load and the speed generates friction, intense heating and wear of the profiles in contact and impacts the performance of the gears. One of the modes of gear failure is wear, and in addition it affects other damage modes [1, 2]. According to the models of wear based on the law of Archard [2, 3, 4, 5] and developed for the gears, the rate of wear is directly related to the contact pressure, to the sliding distance of each contact point and with tribo-mechanical characteristics (coefficient of friction, lubrication condition, hardness or Young's modulus) of the materials in contact. Other authors have studied the wear of gears based on the concept of intensity of power dissipation by postulating that the wear of the material is controlled by the dissipation of energy due to friction between surfaces. This is the case of Onishchenko [6], Wojnarowski and Onishchenko [7].

Wu and Cheng [8] developed a wear model for partial elasto-hydro-dynamic (EHD) contacts including the role of roughness and local temperatures in contact.

The work of Thaer OSMAN [2] concerns influence of wear on the static and dynamic behavior of gears transmission. OSMAN reported a summary of existing wear laws and those applied to gears. It emerges from its observation and that of other authors that, the wear model of Flodin and Anderson [14, 15] resulting from the law of Archard which calculates the wear of each point on the contact profile is appropriate of the wear of the gears; (the simulation agree with the tests results). The experimental results agree well with those of the models, for metallic gears, with a zero wear rate at the pitch point. Unlike metallic gears, the experimental wear results for plastic gears and their composites show a non-zero wear rate at the pitch point $[9,10]$. The previously established wear models giving a zero wear rate 
at the pitch point prove to be unsuitable for predicting the wear of plastic gears and their composites. There are a number of experimental works on the plastic meshing against metal [12]. On the other hand, there are only a few experimental works on the wear of profiles in plastic gears, in particular the works of Mao et al [9] and those of S.N. Kukureka et al [12].

This observation led us to develop a wear law model for predicting the wear of plastic gears and their composites. This work includes firstly, a theoretical study of the modeling of the wear law, then a numerical simulation is made using Matlab software. The results from the simulation are presented and analyzed.

\section{II- THEORETICAL STUDY OF THE MODELING OF THE WEAR LAW}

\section{A- Choice of the wear law model for gears made of polymeric materials}

\section{1-The shape of the worn profile of the gears made of polymeric materials}

The literature reports a number of studies on experimental studies of the wear of both metallic and plastic gears. These works show that two types of tests are often carried out: the simulated gear test by double discs and the real gear test on a gear test bench $[4,9,11,12,13]$. Gear bench tests provide the actual worn tooth profile. The rate of wear in terms of profile depth loss per gear cycle clearly reflects the shape of the worn profile and this is what is widely used in this kind of wear test. Two methods are used to measure the wear rate: real-time measurement by the machine and measurement after shutdown, cooling and cleaning. This second method gives greater precision.

For metallic gears, we observe that the worn profile respects the analytic law, of maximum wear at the top and at the foot of the tooth, and almost no wear at the pitch point [4]. For gears made of polymeric materials, the wear rate is not zero at the pitch point and the worn profile is presented as shown by the work of Düzcükoğlu [11] in Figure 1. The shapes of worn profile shown by the work of Mao [9] Figure 2, does not reflect reality because the tests are carried out until the complete failure of the teeth, but in these conditions towards the end of the test, the ideal wear law is no longer respected.

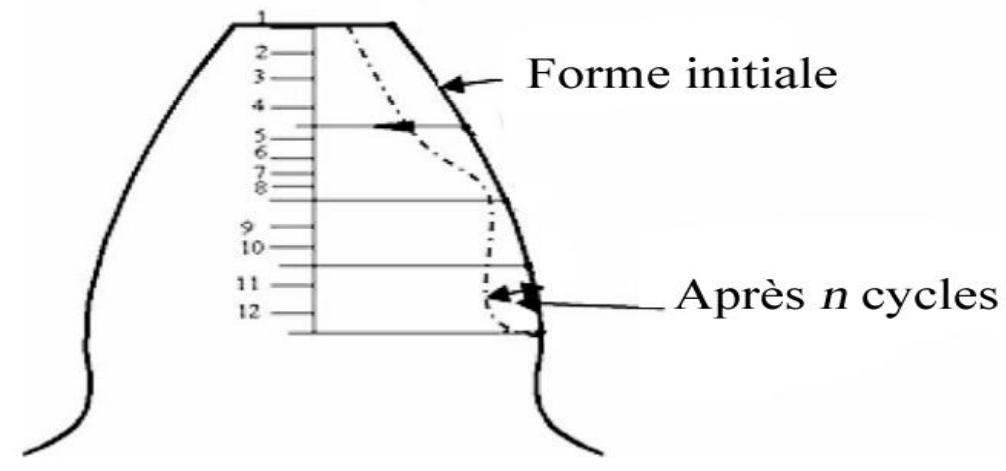

Figure 1- Change in tooth shape with wear. Adapted of Düzcükoglu [11]
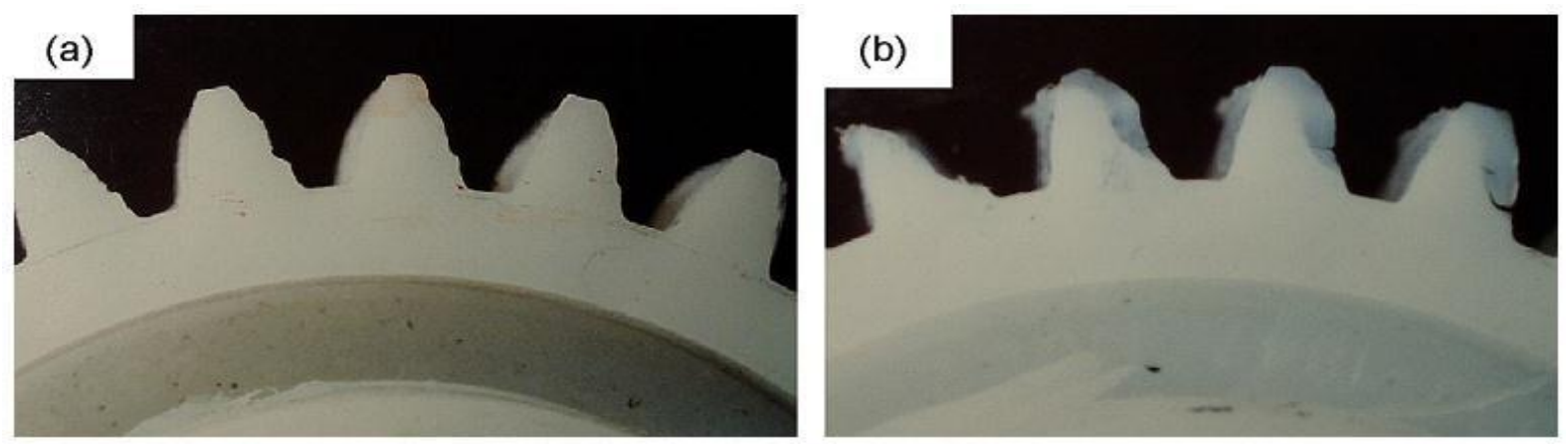

Figure 2- Acetal gear wear forms under loads of (a) $7 \mathrm{Nm}$ and (b) $10 \mathrm{Nm}$ [9] K. MAO 


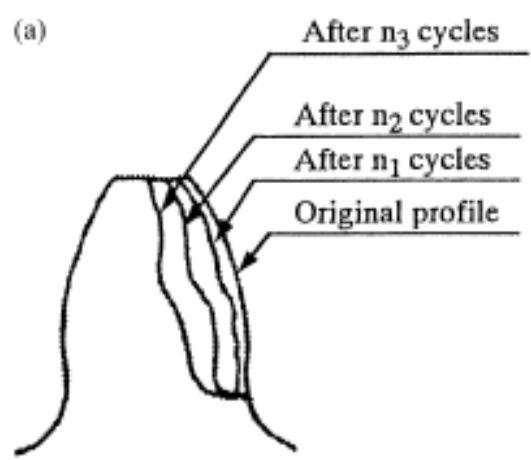

(b)

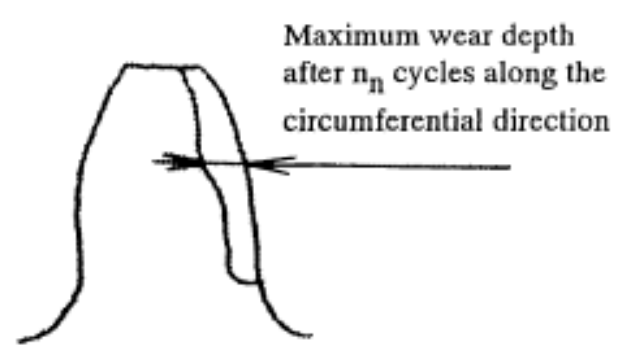

Figure 3- Schematic drawings of tooth profile change (a) and measurement of wear depth (b) [13] M. Kurokawa et al.

Figure 3 shows a diagram of the evolution of the tooth profile change due to wear (a) and the method of measuring the tooth profile wear of plastic gears.

\section{2- Choice of the model of the wear law for gears made of polymeric materials}

Conventionally, the wear phenomenon is quantified by the volume or mass of material loss. But in the case of gears, knowledge of the wear depth per cycle is more useful. This is why, starting from the initial formulation of the law of Archard, global or local expressions of the law of usury were used by various authors. Flodin and Anderson, developed this model, to calculate the depth of wear (h) at each point on the profile of spur and helical gear teeth in the form:

$$
\frac{d h}{d s}=k \cdot P \Rightarrow h=k \cdot \int_{0}^{s} P . d s=k \cdot \int_{0}^{t} P \cdot v_{s} \cdot d t
$$

With: $\mathrm{k}$, the wear coefficient $\left(\mathrm{m}^{2} / \mathrm{N}\right)(\mathrm{k}=\mathrm{K} / \mathrm{H})$.

$$
\begin{aligned}
& \text { P: Contact pressure }\left(\mathrm{N} / \mathrm{m}^{2}\right) \\
& \text { s: Sliding distance }(\mathrm{m}) \\
& \mathrm{v} \text { : Sliding speed }(\mathrm{m} / \mathrm{s}) \\
& \text { t: Sliding time (s) }
\end{aligned}
$$

It emerges from our bibliographic study that unanimously, the wear law of Flodin and Anderson [14, 15] resulting from the law of Archard is more suitable for gears, because it allows to calculate the depth of wear of each point on the contact profile and that the results of the simulations also agree with the results of the experimental tests.

We will therefore stay in line with the most common models in the literature (in particular those of Flodin and Anderson [14, 15]) by also using an Archard law.

We are going to develop a new wear model still based on Archard's law by replacing the wear coefficient k by the compliance $1 / \mathrm{E}^{\lambda}$ to take into account the very sensitive effect of elastoviscoplastic materials on temperature. In the presence of lubricant, the equivalent $\mathrm{E}$ which will be determined using rheological models will be used.

In order to be able to make comparisons, we will also adapt the Flodin model to plastic gears by otherwise determining the sliding distance with a new approach [16] which gives a non-zero sliding distance at the pitch point.

\section{B- Theoretical analysis of the modeling of the wear law}

Starting from our hypothesis that the compliance 1/E assigned of an exponent, can replace the wear coefficient $\mathrm{k}$ in the wear model of Archard suitable for gears, we formulate our new law as follows:

$h_{i}=\frac{P_{i} S_{i}}{E_{i}^{\lambda}}$

The adapted Flodin model is formulated as follows:

$\mathrm{h}_{\mathrm{i}}=\mathrm{k}_{\mathrm{i}} \cdot \mathrm{P}_{\mathrm{i}} \cdot \mathrm{S}_{\mathrm{i}}$

With: $E_{i}$, the equivalent elastic modulus $\left(\mathrm{N} / \mathrm{mm}^{2}\right)$ as a function of temperature of the point considered of the two profiles, 
$h_{\mathrm{i}}$ : Depth of wear per cycle $(\mathrm{mm})$ of the point considered in the profile,

$\mathrm{P}_{\mathrm{i}}$ : Contact pressure $\left(\mathrm{N} / \mathrm{mm}^{2}\right)$ of the point considered in the profile,

$\mathrm{S}_{\mathrm{i}}$ : Sliding distance $(\mathrm{mm})$ of the considered point of the profile,

$\lambda$ : Exponential coefficient of wear (dimensionless) to be determined experimentally,

$\mathrm{k}_{\mathrm{i}}$ : the wear coefficient $\left(\mathrm{m}^{2} / \mathrm{N}\right)$ of the point considered in the profile.

As has been said, the wear coefficient (k) covers a number of physical properties and phenomena depending, on the couple of materials in contact, the lubrication conditions, the sliding speed, the contact pressure, temperature, etc.

It goes without saying that $1 / \mathrm{E}^{\lambda}$ also depends on the properties of the pair of materials and the operating parameters. But it is obvious that by using an equivalent $E$ determined by viscoelastic rheological model which takes into account the temperature and the lubrication, the exponential coefficient of wear $\lambda$ will be little dependent on the above mentioned parameters than is the wear coefficient $(\mathrm{k})$. It would even be probable that the variation of $\lambda$ according to the normalized position for a given operating condition is negligible; it will then be possible to consider $\lambda$ constant according to the normalized position.

\section{1- Study of the determination of the exponential wear coefficient $\lambda$}

The coefficient $\lambda$ is determined by experimental method. The experimental method consists in obtaining the wear depth $\left(\mathrm{h}_{\mathrm{i}}\right)$ of several points of the profile by the wear test on the gear test bench. Then, we determine the values of the contact pressures $\left(\mathrm{P}_{\mathrm{i}}\right)$ and the sliding distance $\left(\mathrm{S}_{\mathrm{i}}\right)$ of each of these points of the profile by calculation and then we deduce the values of the exponential coefficient of wear $(\lambda i)$ of each point on the profile.

\section{2- Study of the determination of the wear coefficient $\mathbf{k}_{\mathbf{i}}$}

There are two methods for determining the wear coefficient $(\mathrm{k})$ which are the experimental method and the statistical regression method.

The experimental method consists in obtaining the wear depth $\left(\mathrm{h}_{\mathrm{i}}\right)$ of several points of the profile by the wear test on the gear test bench. Then, the values of the contact pressures $\left(\mathrm{P}_{\mathrm{i}}\right)$ and the sliding distance $\left(\mathrm{S}_{\mathrm{i}}\right)$ of each of these points of the profile are determined by calculation and then the values of the wear coefficient $\left(\mathrm{k}_{\mathrm{i}}\right)$ of each point on the profile are deduced therefrom. .

The statistical regression method consists in carrying out a statistical analysis of the different parameters that affect the wear coefficient to develop an empirical formula based on these. This is how Janakiraman et al [17] made static analyzes of the parametric effects of load, speed, lubrication and roughness of contact surfaces on wear and proposed an approximate formula for the wear coefficient $(\mathrm{k})$ as follows:

$k=\frac{3.981 \times 10^{29}}{E} \times L^{1.219} \times G^{-7.377} \times S^{1.589}$

$L=\frac{W_{0}}{E R}$

$G=\alpha_{k} E$

$S=\frac{R_{\alpha}^{c}}{R}$

$\frac{1}{E}=\frac{1}{2}\left[\frac{1-v_{1}^{2}}{E_{1}}+\frac{1-v_{1}^{2}}{E_{2}}\right]$

$\frac{1}{R}=\frac{1}{R_{1}}+\frac{1}{R_{2}}$

$R_{\alpha}^{c}=\sqrt{R_{\alpha 1}^{2}+R_{\alpha 2}^{2}}$

With:

L: the dimensionless load.

G: the dimensionless pressure-viscosity coefficient.

S: dimensionless amplitude of roughness.

$\mathrm{E}_{1}, \mathrm{E}_{2}, \mathrm{E}$ respectively the modulus of elasticity of the pinion material, the wheel and the equivalent modulus of elasticity $\left(\mathrm{N} / \mathrm{mm}^{2}\right)$ $v_{1}$ and $v_{2}$ are the Poisson coefficients of the materials of the pinion and the gear. 
$\mathrm{W}_{0}$ the normal load per unit of width $(\mathrm{N} / \mathrm{mm})$.

$R_{1}$ and $R_{2}$ the radii at the point of contact (mm).

$R \alpha_{1}$ and $R \alpha_{2}$ are the roughness of the two contact surfaces (mm).

$\alpha_{\mathrm{k}}$ the pressure-viscosity coefficient with $\alpha_{\mathrm{k}}=1$ for a meshing without lubrication.

\section{3- Study of the determination of the sliding distance $S_{i}$}

The sliding distance will be determined by the new approach based on an analytical-numerical method for the calculation of the sliding distance of the points of the profile of the tooth during the gear meshing, which we previously developed in $\mathrm{N}$. AGBETOSSOU et al. [16]. This method gives a non-zero sliding distance at the pitch point.

\section{4- Study of the determination of the contact pressure $P_{i}$}

In the numerous works which have been carried out on the wear of different types of gears, the determination of the contact pressure (p) is made either by the Hertzian contact method or by the finite element method. As for the value of (P), many authors have used a static (p) and only a few authors have used a dynamic (p). J. Zhang and L. Xianzeng [18] reported in their literature review many authors who have used either of the above methods.

As part of our study, we will use a static contact pressure determined by the Hertzian method.

So after taking into account the load distribution factor taken up by a tooth in the case of plastic meshing, we obtain the maximum value of the Hertzian contact pressure by the formula:

$P_{\text {imax }}=\frac{2 W_{i}}{\pi b_{i} l} \quad(10)$;

$\mathrm{W}_{\mathrm{i}:}$ is the load transmitted along the line of action to the main tooth meshing at the position Spn(i);

bi: is the half contact width of Hertz;

$1:$ is the width of the tooth.

During the sliding, the value of the contact pressure varies from zero at the moment of contact, then increases to the maximum value at the theoretical contact position of the point considered, and then decreases until the value zero at the time of leaving the contact zone.

On a: $P_{i}=P_{\operatorname{imax}} \sqrt{1-\left(\frac{x}{b_{i}}\right)^{2}}$

With $\mathrm{x}$ varying from - bi to + bi.

As the value of the half width of Hertz is very small, we have, in the very close vicinity of -bi and +bi, the values of $P_{i}$ which are practically equal to the value of $\mathrm{P}_{\mathrm{imax}}\left(\mathrm{P}_{\mathrm{i}}>0.99 \mathrm{Pimax}\right)$. If we also consider the impact effect of coming into contact, we can then work with $\mathrm{P}_{\text {imax }}$ over the entire $2 \mathrm{~b}_{\mathrm{i}}$ contact area. This has been the practice by several authors who have dealt with the subject on the wear of gears, and as part of our study, we will also work with the maximum contact pressure of Hertz $\mathrm{P}_{\text {imax. }}$.

\section{1- Characteristics data and curves used for the simulation \\ III- NUMERICAL SIMULATION}

For the present simulation, we will use the results of K. MAO (figure 4) [9] obtained by the test on a gear test bench for acetal gears. The experimental results only give us the wear rate of a single point on the profile of the tooth that of the pitch point as a function of the number of cycles. 


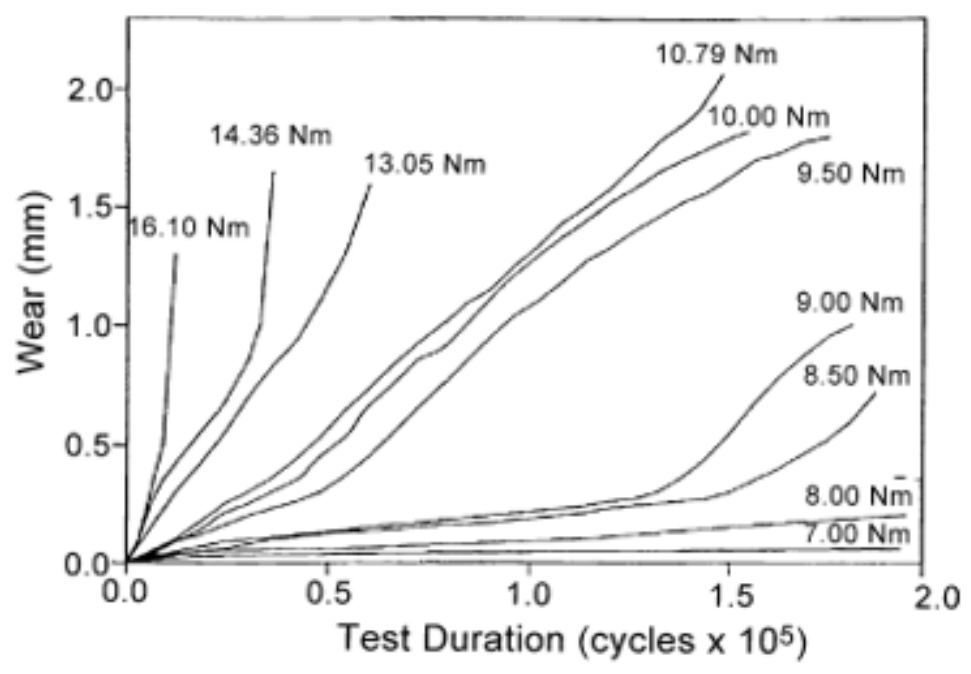

Figure 4- Pitch point wear test for acetal gears $(\omega=1000 \mathrm{rpm})$.

The table 1 presents the geometrical characteristics for the gears that are used to perform the tests done by K. MAO. All the tests are performed with the angular velocity $\omega=1000 \mathrm{rpm}$ and with the loads that varying from $7 \mathrm{Nm}$ to $16.10 \mathrm{Nm}$ as shown by the figure 4.

Table 1: Geometrical Characteristics of the gears for the test of K. MAO [9]

\begin{tabular}{|l|l|}
\hline Module & $2 \mathrm{~mm}$ \\
\hline Number of tooth & 30 (for the two gears) \\
\hline Pressure angle & $20^{\circ}$ \\
\hline Tooth wide & $17 \mathrm{~mm}$ \\
\hline Nominal backlash & $0.18 \mathrm{~mm}$ \\
\hline Tooth thickness & $3.14 \mathrm{~mm}$ \\
\hline Contact ratio & 1.65 \\
\hline Material 1 & Acetal (Derlin 100) \\
\hline Material 2 & Acetal (Derlin 100) \\
\hline
\end{tabular}

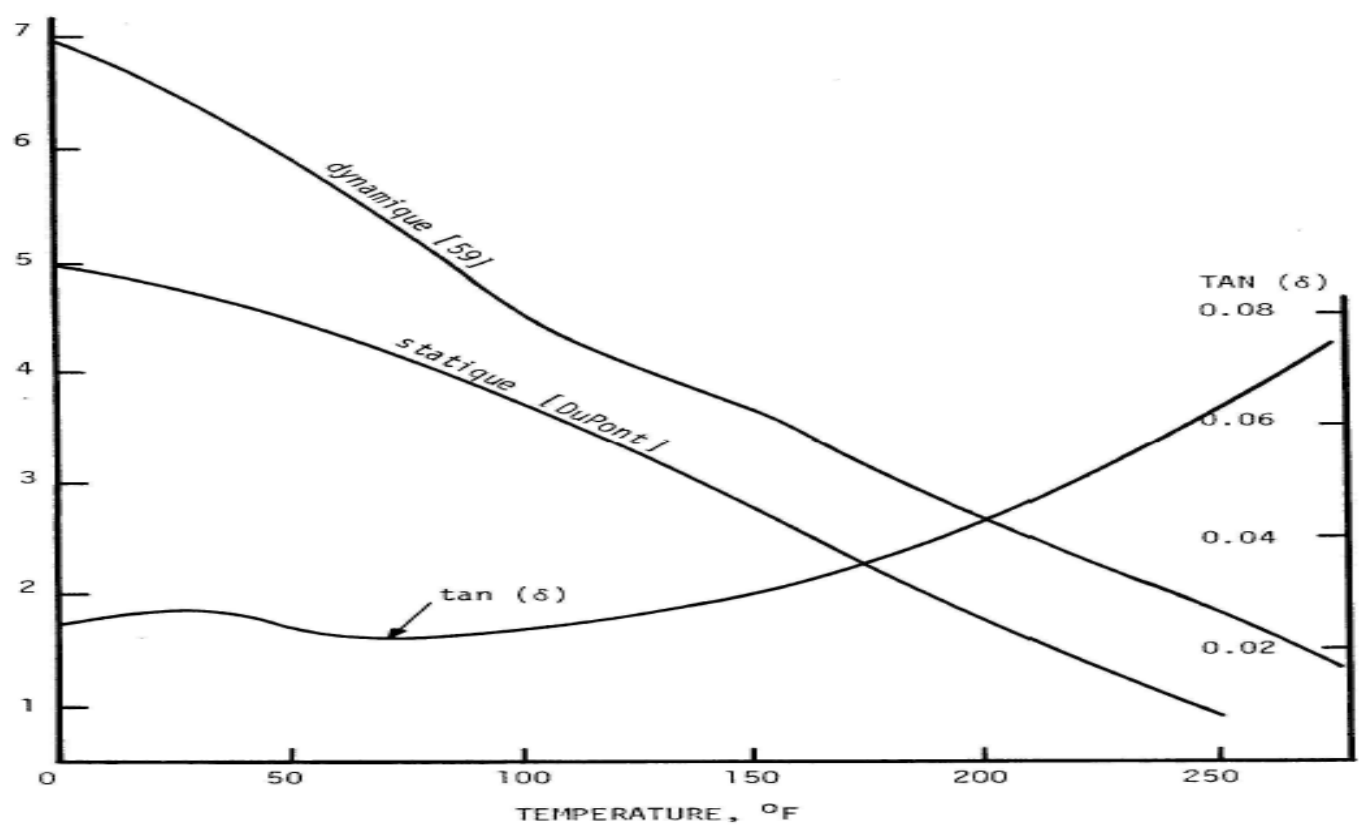

Figure 5- Variation of elasticity modulus with temperature for homopolymer acetal [3], modulus E is expressed in $10^{5} \mathrm{Psi}$. 
The figure 5 is the static and dynamic DMA curve for homopolymer acetal. Its gives the variation of elasticity modulus as a function of the temperature.

The static DMA curve of homopolymer acetal can be modeled by the straight line passing through points $\mathrm{A}\left(100^{\circ} \mathrm{F}, 367000\right.$ Psi) and $\mathrm{B}\left(250^{\circ} \mathrm{F}, 100000 \mathrm{Psi}\right)$ that is also $\mathrm{A}\left(100^{\circ} \mathrm{F}, 2530.377 \mathrm{MPa}\right)$ and $\mathrm{B}\left(250^{\circ} \mathrm{F}, 689.476 \mathrm{MPa}\right)$ which equation is :

$$
\mathrm{E}=-12.27 \mathrm{~T}_{\mathrm{f}}+3757 \quad(12) \quad \mathrm{T}_{\mathrm{f}} \text { in }{ }^{\circ} \mathrm{F} .
$$

\section{2- Method of determining the equilibrium and instantaneous temperatures}

Research in the field of the thermal study of plastic gear meshing has been refined over the years to the point that the thermal models commonly used today have taken into account all the parameters that affect the meshing such as the geometry, of the material and those of the operating conditions. Therefore, these models give satisfactory prediction results which are in agreement with the experimental results. In this present work we will use the method proposed by the work of KOFFI et al [3] (1987). For full details of the method, reference can be made to the reference document [3]. Indeed the KOFFI model was established on the main works which preceded it such as the works of Hackman and Strikle (1966), of Youssef S. (1975), of Girard P. (1978), of Bosshart H. (1975), Yelle H. and Poupard M. (1975), Tsukamoto N. and Yano T. (1978), Takanashi S. and Sohoji A. (1980), ESDU (Engineering Science Data Unit) (1981) and the work of Gauvin R. and Girard P. (1981). Its objective is to group and complete all the parameters of the meshing studied in the previous models, to simplify the calculation of certain factors of the previous models while keeping their precision and to separate the calculation of the equilibrium temperature and that of the instantaneous temperature. In short, it is a numerical model, which used the finite difference method to solve the thermal equations of heat transfer, which took into account the three different temperatures in presence namely: room temperature, equilibrium and instantaneous . The model took into account the permanent or transient state of the thermal phenomena present, the load sharing factor specific to the plastic mesh, the heat distribution factor between the pinion and the gear. The model has finally sought the simplified method for the calculation of certain parameters and proposes a computer program for the calculations. The original program in FORTRAN was written in 1986 by Professor Koffi Demagna. This program is translated from FORTRAN, updated and written in Matlab for use in this simulation.

\section{3- The simulation procedure}

From the geometrical and operational data used to conduct the experimental tests, the distribution of the equilibrium temperature in the tooth and the evolution of the instantaneous temperature on the profile are determined according to the normalized positions using the program of calculating temperatures. The calculated instantaneous temperatures make it possible to determine the values of the modulus of elasticity as a function of the temperature and of the normalized position using the equation of the DMA curve. The hertz pressure $\mathrm{Pi}$ and the sliding distance $\mathrm{Si}$ are also calculated for each normalized position. The exponential wear coefficient $(\lambda i)$ is determined for the pitch point and is assumed to be constant for all normalized positions. 


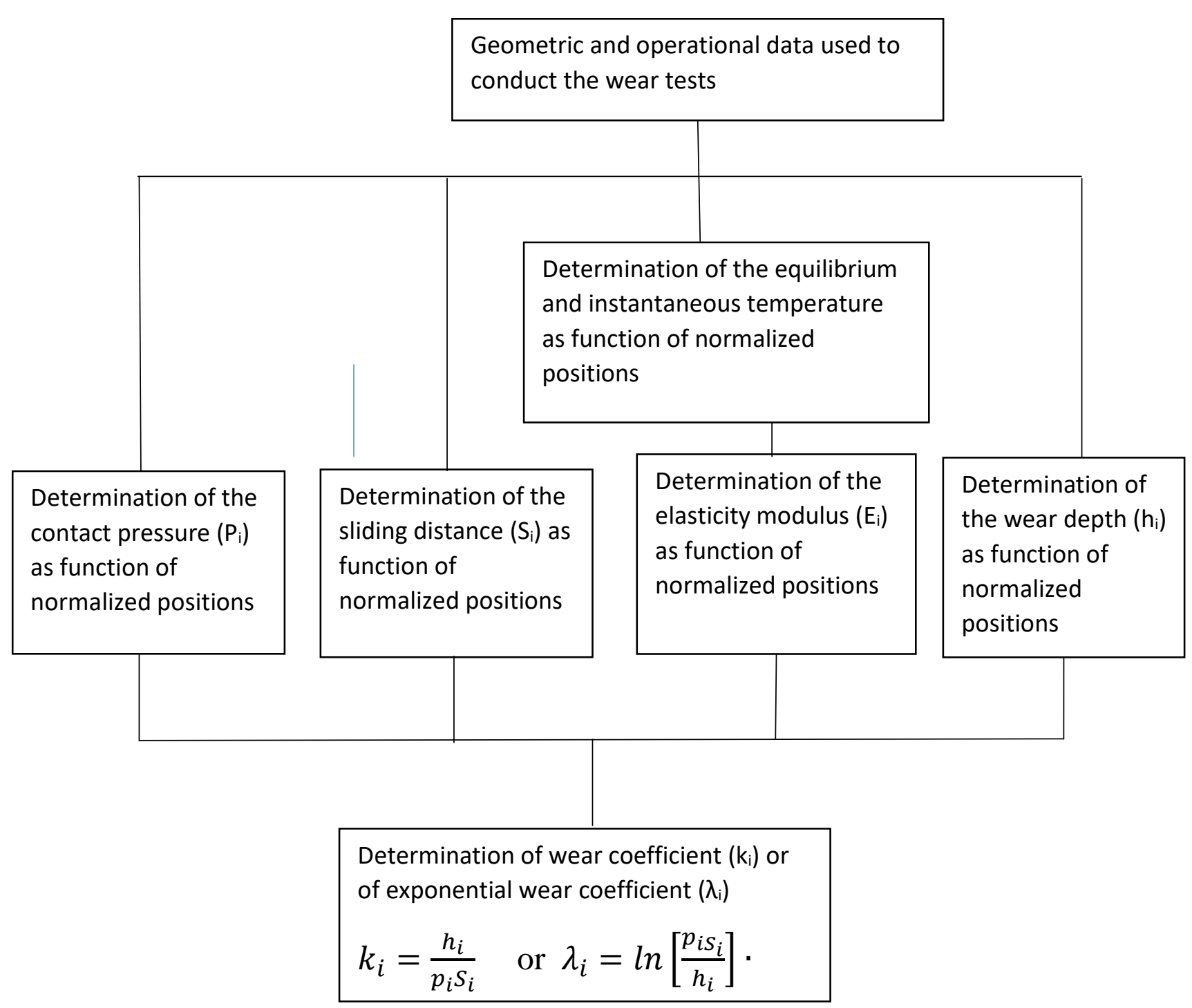

Figure 6- Flowchart for the determination of wear coefficient $(k)$ and exponential wear coefficient $(\lambda)$

The calculation method determines the wear coefficient (ki) for each normalized position. But the value of the roughnesses $\mathrm{R}_{\alpha 1}$ and $R_{\alpha 2}$ introduced into the formulas is supposed to be constant and equal to that of the pitch point. It is determined so that the model wear rate is equal to the experimental wear rate. The flowchart for determining the wear coefficients $(\lambda \mathrm{i})$ and $(\mathrm{ki})$ is summarized in Figure 6. After calculating all the parameters, the values are entered into the model formulas to simulate wear over the entire tooth profile.

Using our Matlab programs developed for this purpose, the numerical results are obtained and presented in the following section.

\section{IV- RESULTS AND DISCUSSIONS}

In this section, we will present the main results from our simulations and analyze them. Then with the available experimental results, we will propose a method of validation of our new wear model.

\section{1- Results for simulated operating conditions}

The results relate to the Delrin 100 acetal material which was used for the wear tests. The different simulated operating conditions constitute case studies. The results are presented in the form of a graph in general, but also with tables. Each simulated case always begins with the determination of the equilibrium and instantaneous temperatures of the pinion and the gear, but their graphic results are not generally presented except in a few cases. 
Case study I: Delrin 100 acetal pinion and gear; $\mathrm{Z1}=\mathrm{Z2}=30$ teeth; module $\mathrm{m}=2 \mathrm{~mm}(\mathrm{Pd}=12.7)$; pressure angle $\alpha=20^{\circ}$; width of tooth $\mathrm{b}=17 \mathrm{~mm}$; transmitted torque $\mathrm{C}=8 \mathrm{Nm} ;$ rotation speed $\omega=1000 \mathrm{rpm}$. Case study I allows us to study the worn shape on the driving gear and the driven gear, as well as the comparison between the new model and the adapted Flodin model.

Case study II: Delrin 100 acetal pinion and gear; $\mathrm{Z} 1=\mathrm{Z2}=30$ teeth; module $\mathrm{m}=2 \mathrm{~mm}$; pressure angle $\alpha=20^{\circ}$; width of tooth $\mathrm{b}=17 \mathrm{~mm}$; transmitted torque $\mathrm{C}=7 \mathrm{Nm}, 8 \mathrm{Nm}, 8.5 \mathrm{Nm}, 9 \mathrm{Nm}, 9.5 \mathrm{Nm}, 10 \mathrm{Nm}, 10.79 \mathrm{Nm}$; rotation speed $\omega=1000 \mathrm{rpm}$. Case study II allows us to study the influence of the transmitted torque, to study the variation of the wear coefficients ki and $\lambda$, and to validate our new model by establishing the curve of the correction factor Kc of the model. The main results are presented in the figures and tables below.

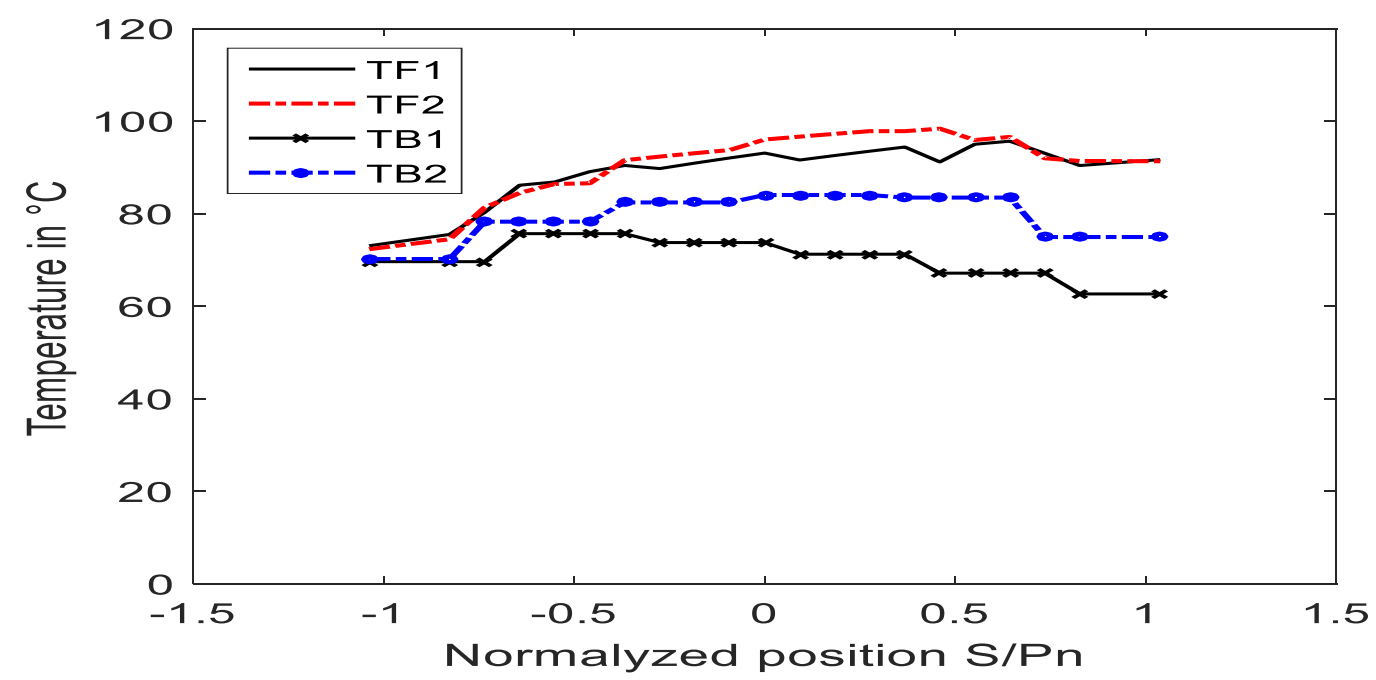

Figure 7.a- Evolution according to the normalized position of the equilibrium temperatures TB1, TB2 and the instantaneous temperatures TF1, TF2 for the driver and the driven gears: acetal/acetal; $\mathrm{C}=8 \mathrm{Nm}, \omega=1000 \mathrm{rpm}$.

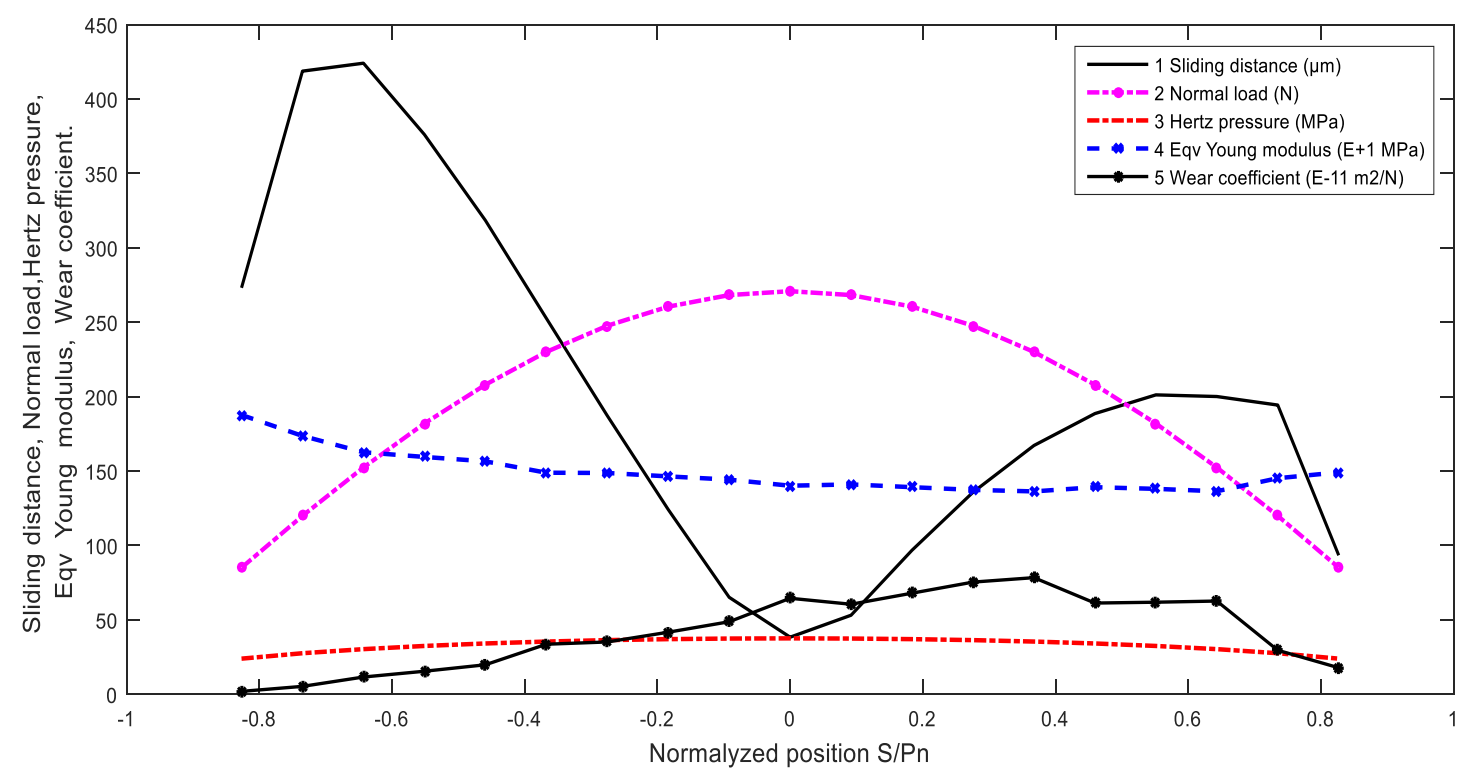

Figure 7.b-Evolution according to the normalized position of the sliding distance, the normal load, the Hertz pressure, the equivalent Young's modulus, and the wear coefficient of the driver gear: acetal/acetal; $C=8 \mathrm{Nm}, \omega=1000 \mathrm{rpm}$; exponential wear coefficient $\lambda=2.920806$. 


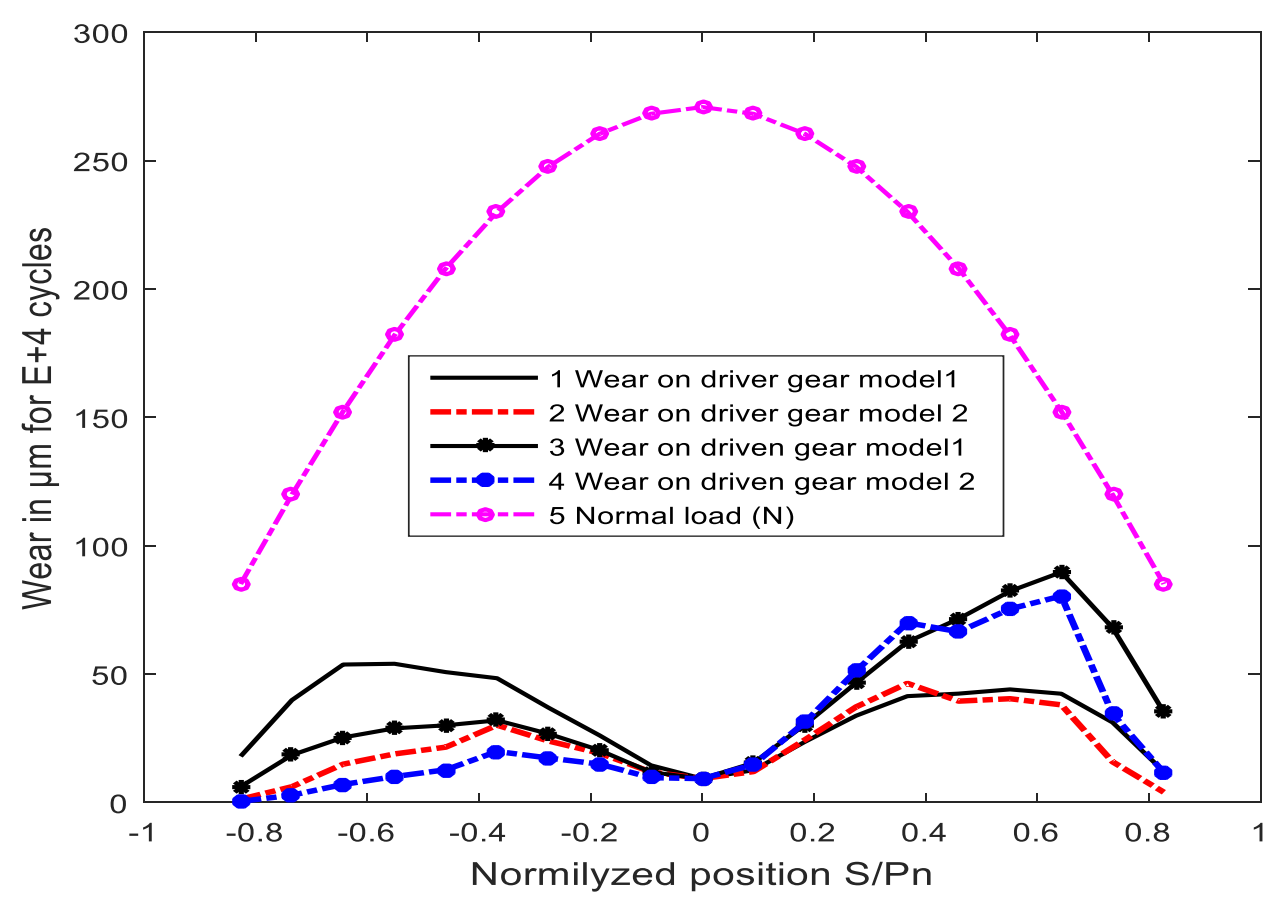

Figure 7.c- Evolution according to the normalized position of the wear on the driver and driven gears; model 1: new model; model 2: Flodin adapted; acetal/acetal; $\mathrm{C}=8 \mathrm{Nm}, \omega=1000 \mathrm{rpm}$; exponential wear coefficient $\lambda=2.920806$.

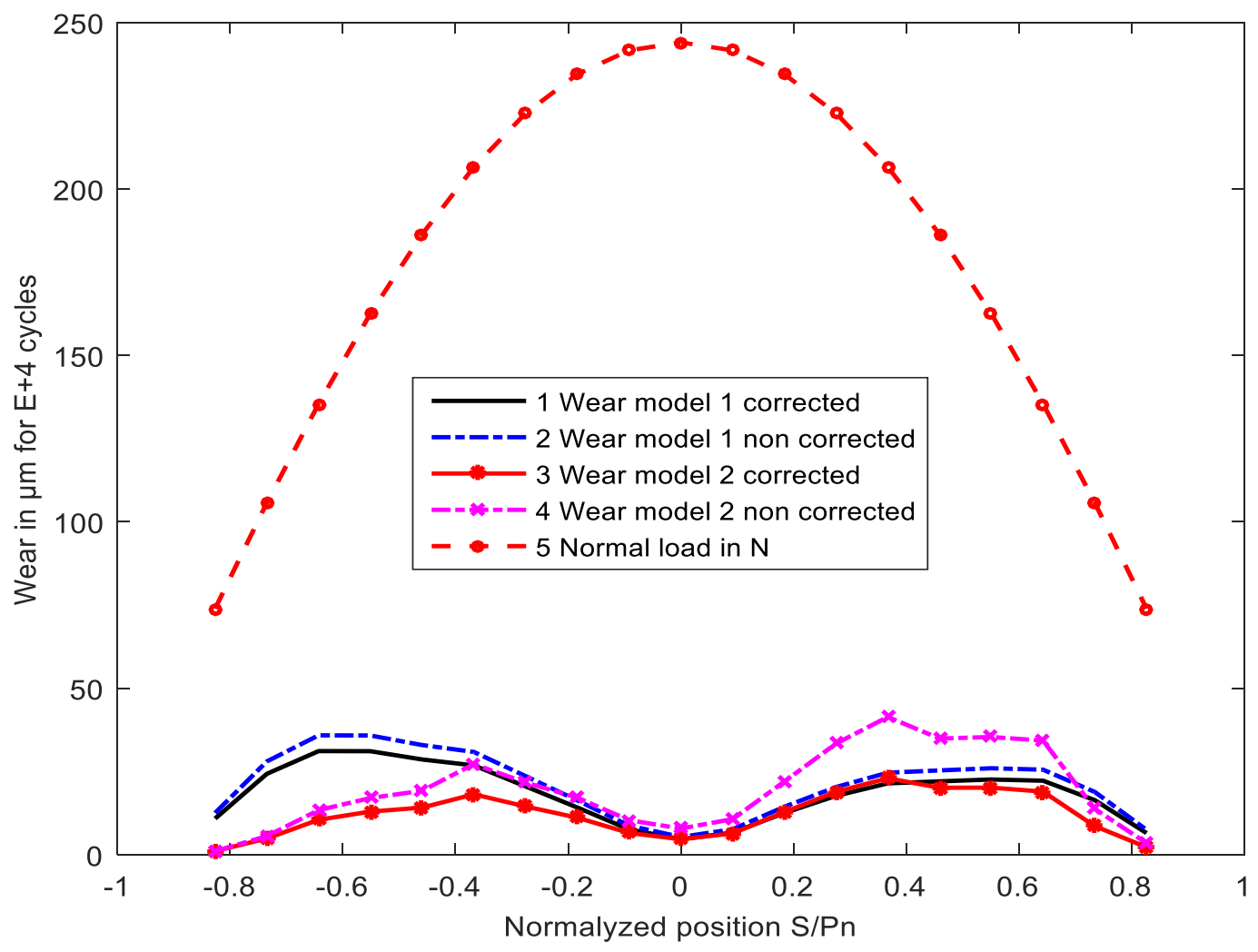

Figure 8.a- Study of the variation of the wear coefficient ki and the exponential wear coefficient $\lambda$ according to the normalized position and according to the torque transmitted for the wear of the driver gear; model 1: new model; model 2: Flodin adapted; acetal/acetal; C=7Nm, $\omega=1000 \mathrm{rpm}$. 


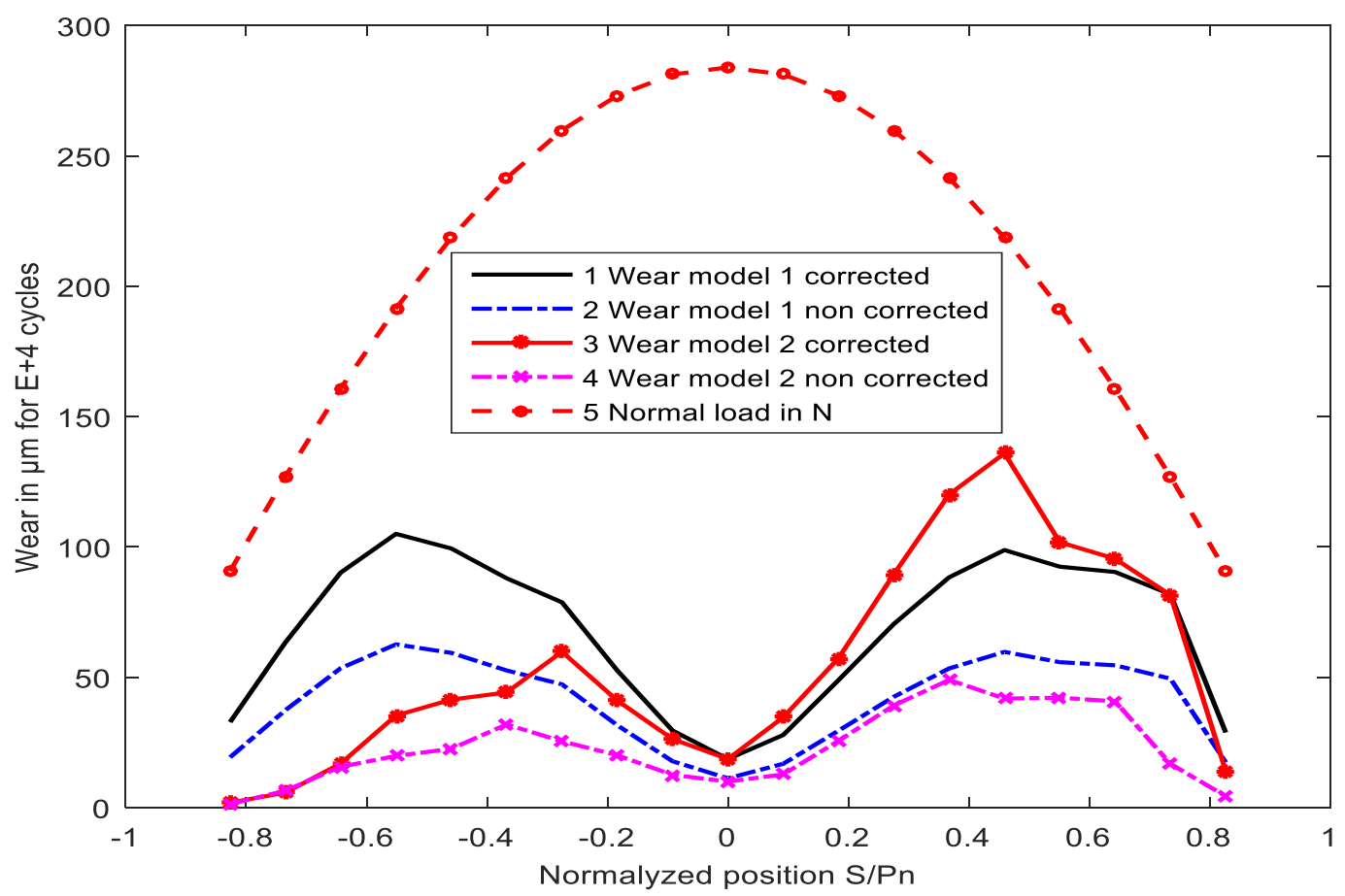

Figure 8.b- Study of the variation of the wear coefficient ki and the exponential wear coefficient $\lambda$ according to the normalized position and according to the torque transmitted for the wear of the driver gear; model 1: new model; model 2: Flodin adapted; acetal $/ \mathrm{acetal} ; \mathrm{C}=8.5 \mathrm{~N} ; \omega=1000 \mathrm{rpm}$.

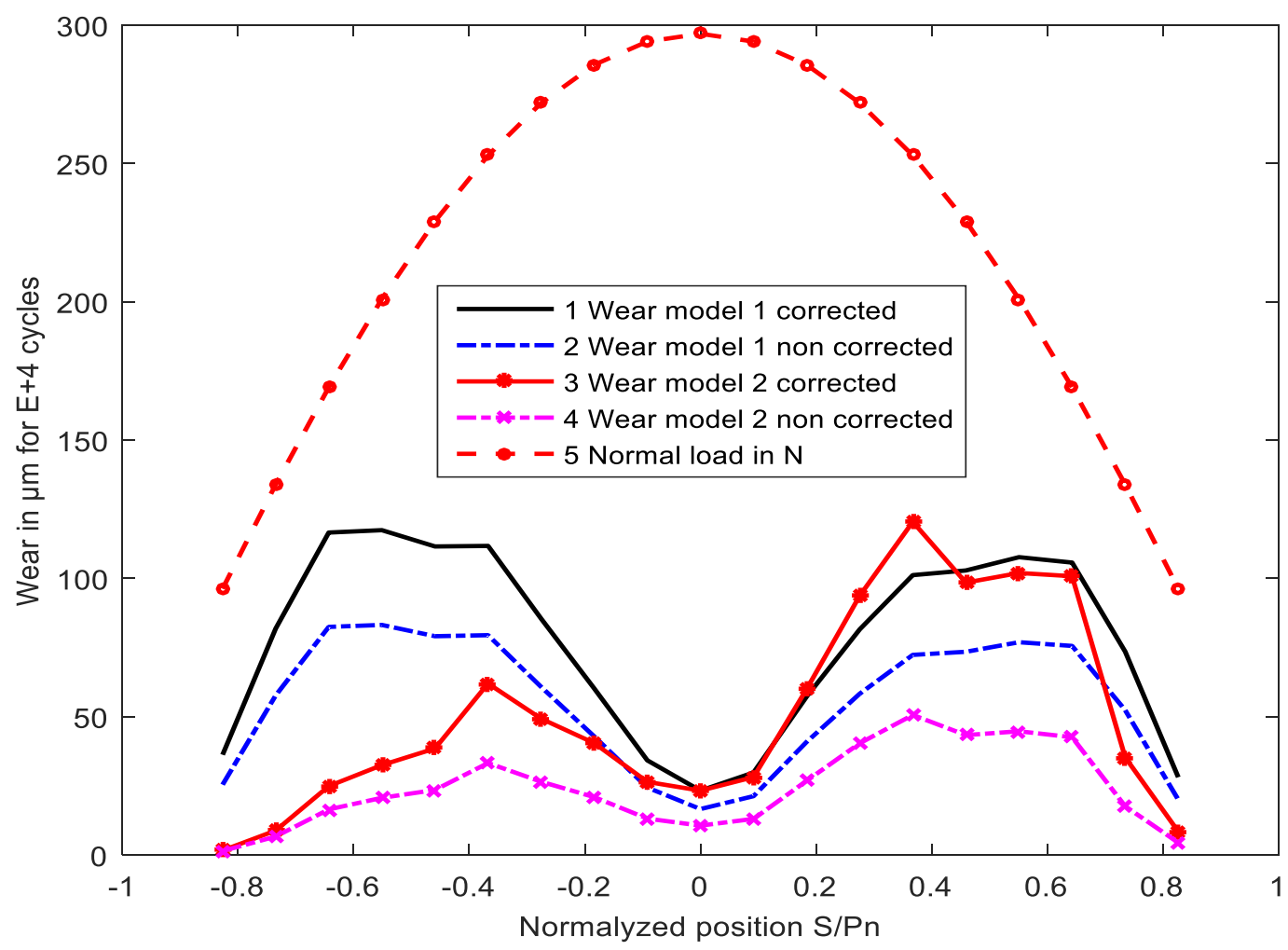

Figure 8.c-Study of the variation of the wear coefficient ki and the exponential wear coefficient $\lambda$ according to the normalized position and according to the torque transmitted for the wear of the driver gear; model 1: new model; model 2: Flodin adapted; acetal/acetal; C=9Nm, $\omega=1000 \mathrm{rpm}$. 


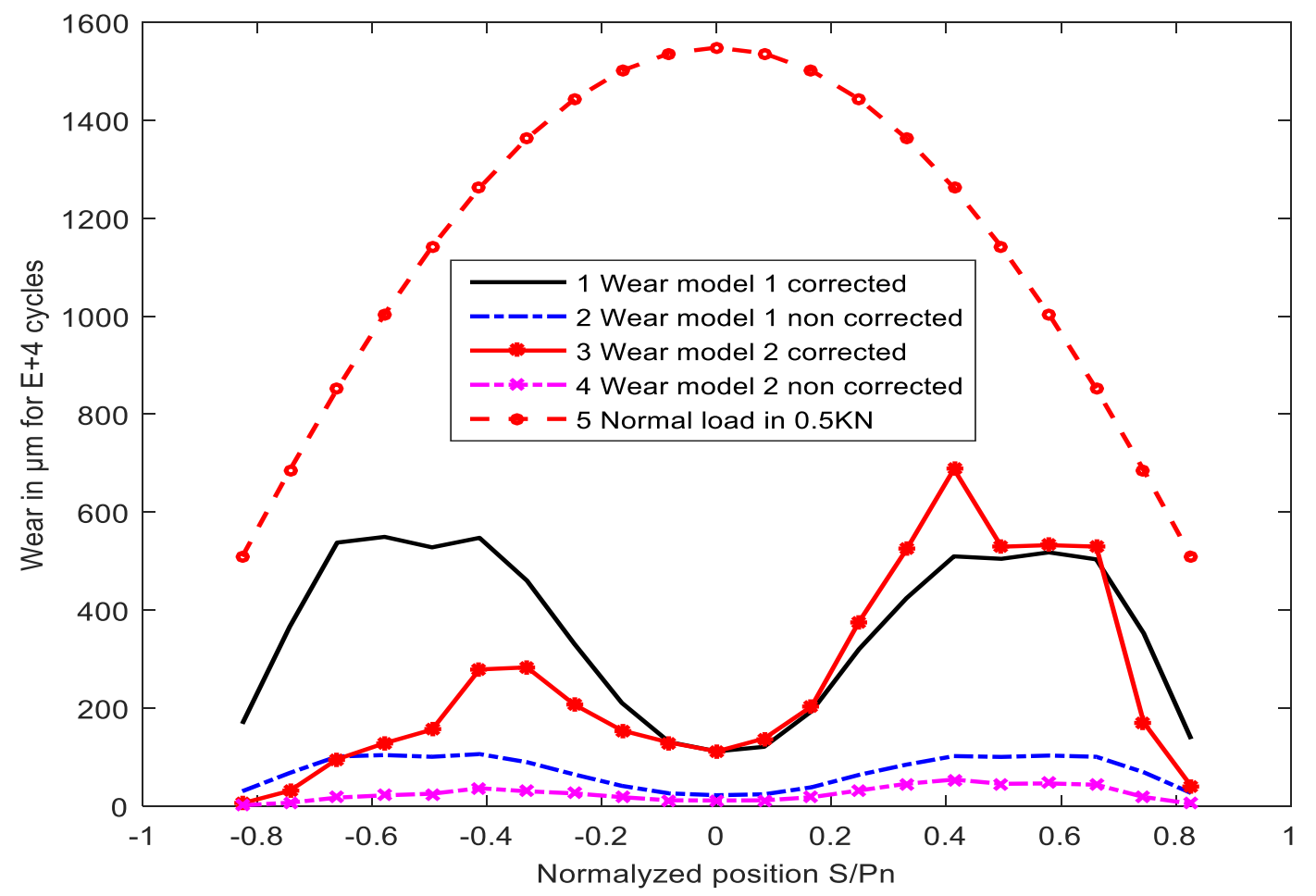

Figure 8.d-Study of the variation of the wear coefficient ki and the exponential wear coefficient $\lambda$ according to the normalized position and according to the torque transmitted for the wear of the driver gear; model 1: new model; model 2: Flodin adapted; acetal/acetal; C=9.5Nm; $\omega=1000 \mathrm{rpm}$.

Table 2: Summary table of the variation of the exponential coefficient of wear $\lambda$ as a function of the load with $\omega=1000 \mathrm{rpm}$.

\begin{tabular}{|c|c|c|c|c|c|}
\hline \multirow[b]{2}{*}{ Load (Nm) } & \multicolumn{2}{|c|}{ Wear rate at pitch point $(\mu \mathrm{m} / \mathrm{cycle})$} & \multirow{2}{*}{$\begin{array}{l}\text { Wear coefficient } \lambda \\
\text { of the model, } \\
\text { determine with the } \\
\text { load } 8 \mathrm{Nm}\end{array}$} & \multirow{2}{*}{$\begin{array}{l}\text { Wear factor of } \\
\text { correction Kc } \\
(\mathrm{Kc}=\mathrm{Ue} / \mathrm{Um})\end{array}$} & \multirow{2}{*}{$\begin{array}{l}\text { Wear coefficients } \lambda \text { i that } \\
\text { give the wear rate Ue for } \\
\text { each load }\end{array}$} \\
\hline & Expérience (Ue) & Modèle (Um) & & & \\
\hline 7 & $4.65 \mathrm{E}-4$ & $5.345 \mathrm{E}-4$ & \multirow{7}{*}{2.920806} & 0.87 & 2.939687 \\
\hline 8 & $9.30 \mathrm{E}-4$ & $9.30 \mathrm{E}-4$ & & 1.00 & 2.920806 \\
\hline 8.5 & $18.60 \mathrm{E}-4$ & $11.19 \mathrm{E}-4$ & & 1.662 & 2.850323 \\
\hline 9 & $23.26 \mathrm{E}-4$ & $16.603 \mathrm{E}-4$ & & 1.401 & 2.873271 \\
\hline 9.5 & $111.63 \mathrm{E}-4$ & $22.04 \mathrm{E}-4$ & & 5.065 & 2.689605 \\
\hline 10 & $134.88 \mathrm{E}-4$ & $31.58 \mathrm{E}-4$ & & 4.271 & 2.710861 \\
\hline 10.79 & $139.53 \mathrm{E}-4$ & $56.588 \mathrm{E}-4$ & & 2.465 & 2.786980 \\
\hline
\end{tabular}

For a given load (the transmitted torque), the exponential wear coefficient $\lambda$ is assumed to be constant over the entire meshing line, so it does not vary according to the normalized position Spn.

Table 3: Summary table of the variation of the wear coefficient ki as a function of the load and according to the normalized position Spn with $\omega=1000 \mathrm{rpm}$.

\begin{tabular}{|l|l|l|l|l|l|l|l|l|l|}
\hline Spn & -0.827 & -0.551 & -0.367 & -0.184 & 0 & 0.184 & 0.367 & 0.551 & 0.827 \\
\hline $\begin{array}{l}\mathrm{ki}: \mathrm{C}=7 \mathrm{Nm} ; \\
\mathrm{Rg}=10.243 \mathrm{E}-6\end{array}$ & $1.93 \mathrm{E}-11$ & $1.18 \mathrm{E}-10$ & $2.24 \mathrm{E}-10$ & $2.71 \mathrm{E}-10$ & $3.81 \mathrm{E}-10$ & $3.96 \mathrm{E}-10$ & $4.35 \mathrm{E}-10$ & $3.53 \mathrm{E}-10$ & $1.16 \mathrm{E}-10$ \\
\hline $\begin{array}{l}\mathrm{ki}: \mathrm{C}=8 \mathrm{Nm} ; \\
\mathrm{Rg}=5.919 \mathrm{E}-6\end{array}$ & $1.96 \mathrm{E}-11$ & $1.55 \mathrm{E}-10$ & $3.36 \mathrm{E}-10$ & $4.17 \mathrm{E}-10$ & $6.45 \mathrm{E}-10$ & $6.79 \mathrm{E}-10$ & $7.84 \mathrm{E}-10$ & $6.19 \mathrm{E}-10$ & $1.78 \mathrm{E}-10$ \\
\hline $\begin{array}{l}\mathrm{ki}: \mathrm{C}=8.5 \mathrm{Nm} ; \\
\mathrm{Rg}=6.633 \mathrm{E}-6\end{array}$ & $2.72 \mathrm{E}-11$ & $2.76 \mathrm{E}-10$ & $4.66 \mathrm{E}-10$ & $8.54 \mathrm{E}-10$ & $1.21 \mathrm{E}-09$ & $1.52 \mathrm{E}-09$ & $1.92 \mathrm{E}-09$ & $1.49 \mathrm{E}-09$ & $5.72 \mathrm{E}-10$ \\
\hline $\begin{array}{l}\mathrm{ki}: \mathrm{C}=9 \mathrm{Nm} ; \\
\mathrm{Rg}=3.5862 \mathrm{E}-6\end{array}$ & $2.23 \mathrm{E}-11$ & $2.43 \mathrm{E}-10$ & $6.27 \mathrm{E}-10$ & $8.06 \mathrm{E}-10$ & $1.41 \mathrm{E}-09$ & $1.52 \mathrm{E}-09$ & $1.86 \mathrm{E}-09$ & $1.41 \mathrm{E}-09$ & $3.37 \mathrm{E}-10$ \\
\hline $\mathrm{Spn}$ & -0.827 & -0.579 & -0.331 & -0.165 & 0 & 0.165 & 0.331 & 0.579 & 0.827 \\
\hline $\begin{array}{l}\mathrm{ki}: \mathrm{C}=9.5 \mathrm{Nm} ; \\
\mathrm{Rg}=5.6852 \mathrm{E}-6\end{array}$ & $7.28 \mathrm{E}-11$ & $9.11 \mathrm{E}-10$ & $3.30 \mathrm{E}-09$ & $4.15 \mathrm{E}-09$ & $6.36 \mathrm{E}-09$ & $6.85 \mathrm{E}-09$ & $8.70 \mathrm{E}-09$ & $7.14 \mathrm{E}-09$ & $1.51 \mathrm{E}-09$ \\
\hline $\begin{array}{l}\mathrm{ki}: \mathrm{C}=10 \mathrm{Nm} ; \\
\mathrm{Rg}=3.3705 \mathrm{E}-6\end{array}$ & $4.89 \mathrm{E}-11$ & $7.67 \mathrm{E}-10$ & $3.22 \mathrm{E}-09$ & $4.12 \mathrm{E}-09$ & $7.20 \mathrm{E}-09$ & $7.38 \mathrm{E}-09$ & $9.82 \mathrm{E}-09$ & $7.94 \mathrm{E}-09$ & $1.43 \mathrm{E}-09$ \\
\hline $\begin{array}{l}\mathrm{ki}:=10.79 N m ; \\
\mathrm{Rg}=1.1506 \mathrm{E}-6\end{array}$ & $1.89 \mathrm{E}-11$ & $4.38 \mathrm{E}-10$ & $1.81 \mathrm{E}-09$ & $3.28 \mathrm{E}-09$ & $6.82 \mathrm{E}-09$ & $6.96 \mathrm{E}-09$ & $1.12 \mathrm{E}-08$ & $7.78 \mathrm{E}-09$ & $1.03 \mathrm{E}-09$ \\
\hline
\end{tabular}

$\operatorname{Rg}$ : Roughness of the tooth profile after wear. 


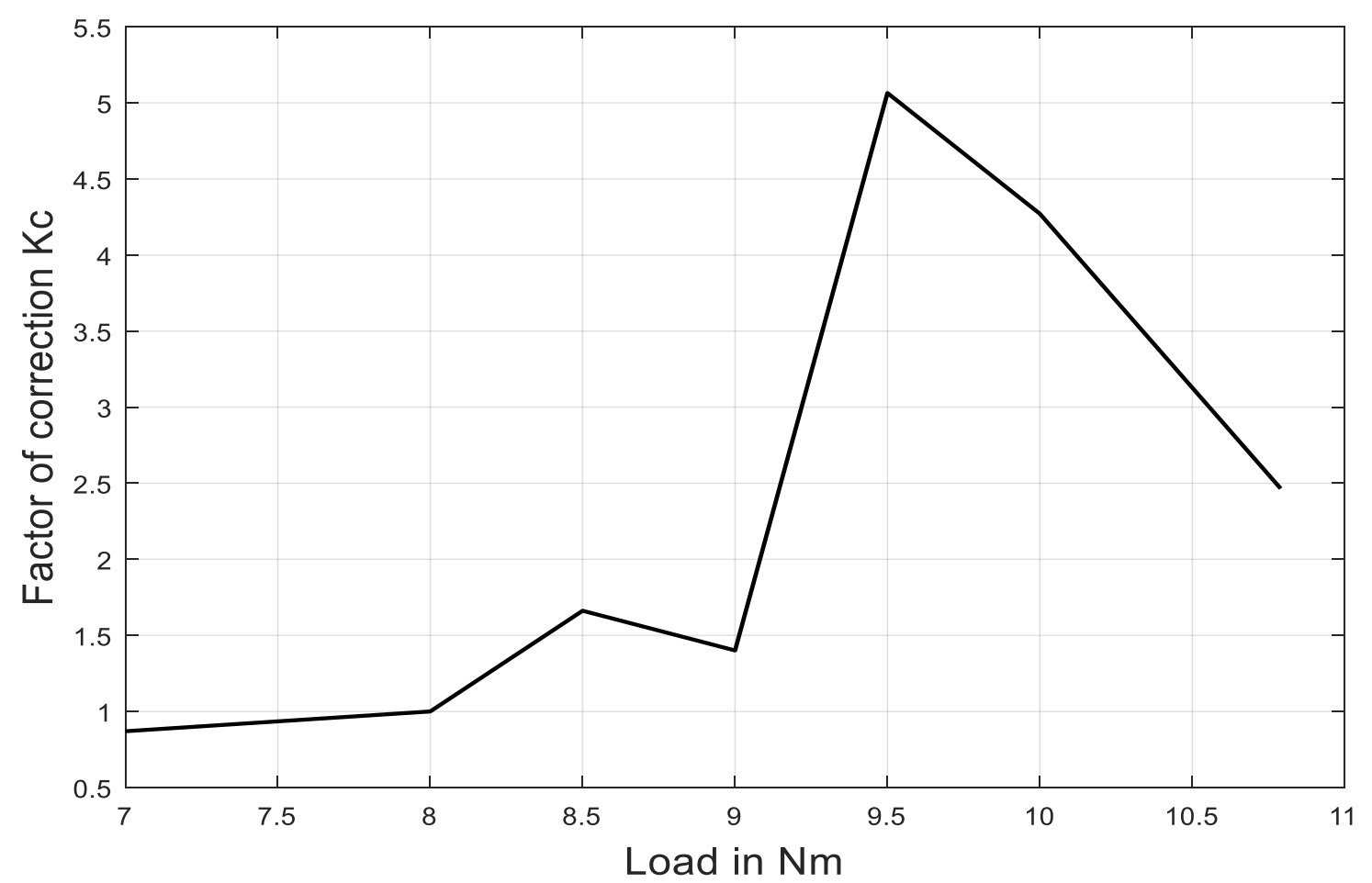

Figure 9- Curve of the correction factor Kc as a function of the load (Obtained by the values in table 2).

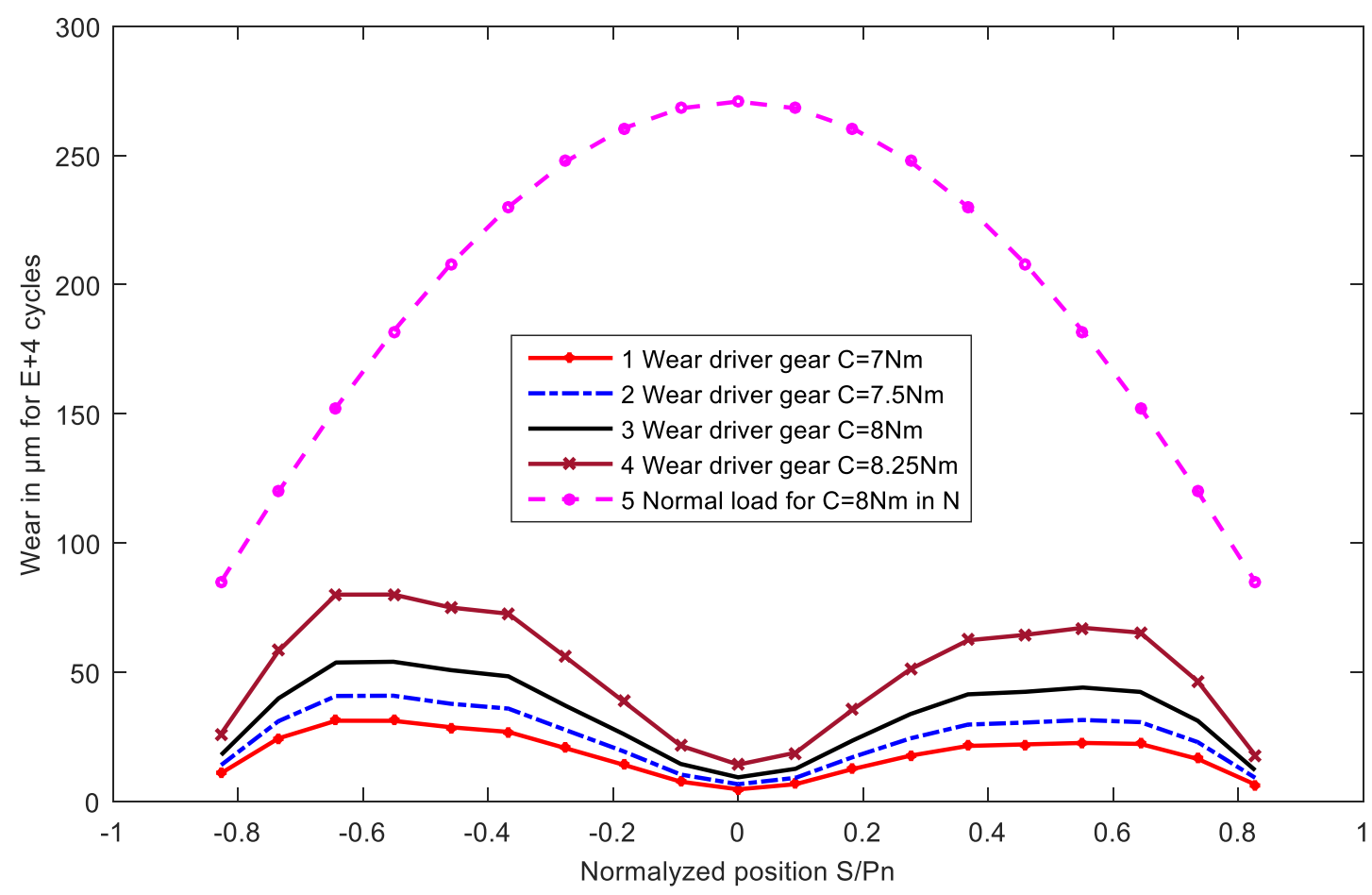

Figure 10.a- Influence of the transmitted torque and Example 1 of application of the validated model for the calculation of the wear of the loads different from those of the experimental tests: $7.5 \mathrm{Nm} ; 8.25 \mathrm{Nm}$. 


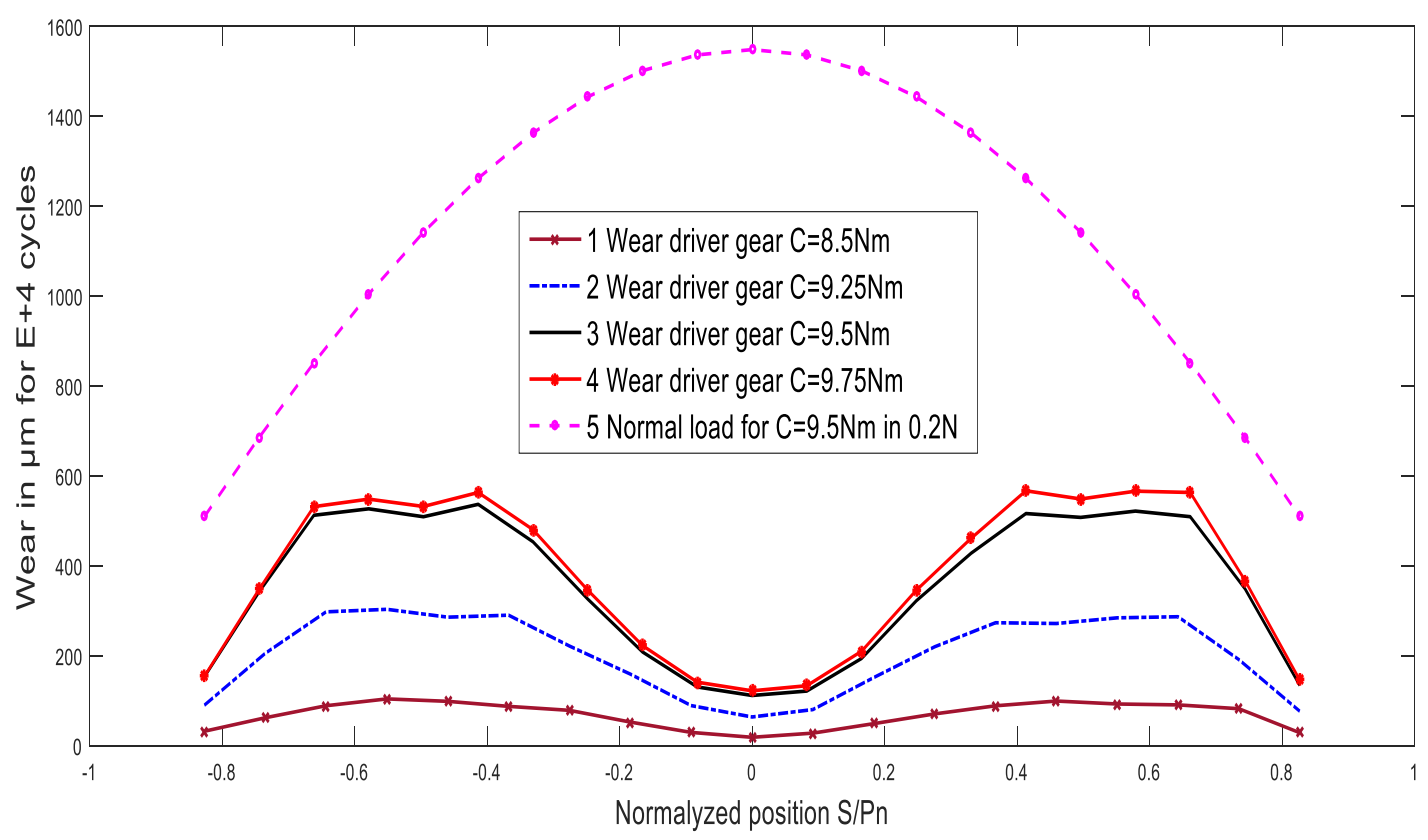

Figure 10.b- Influence of the transmitted torque and Example 2 of application of the validated model for the calculation of the wear of the loads different from those of the experimental tests: $9.25 \mathrm{Nm} ; 9.75 \mathrm{Nm}$.

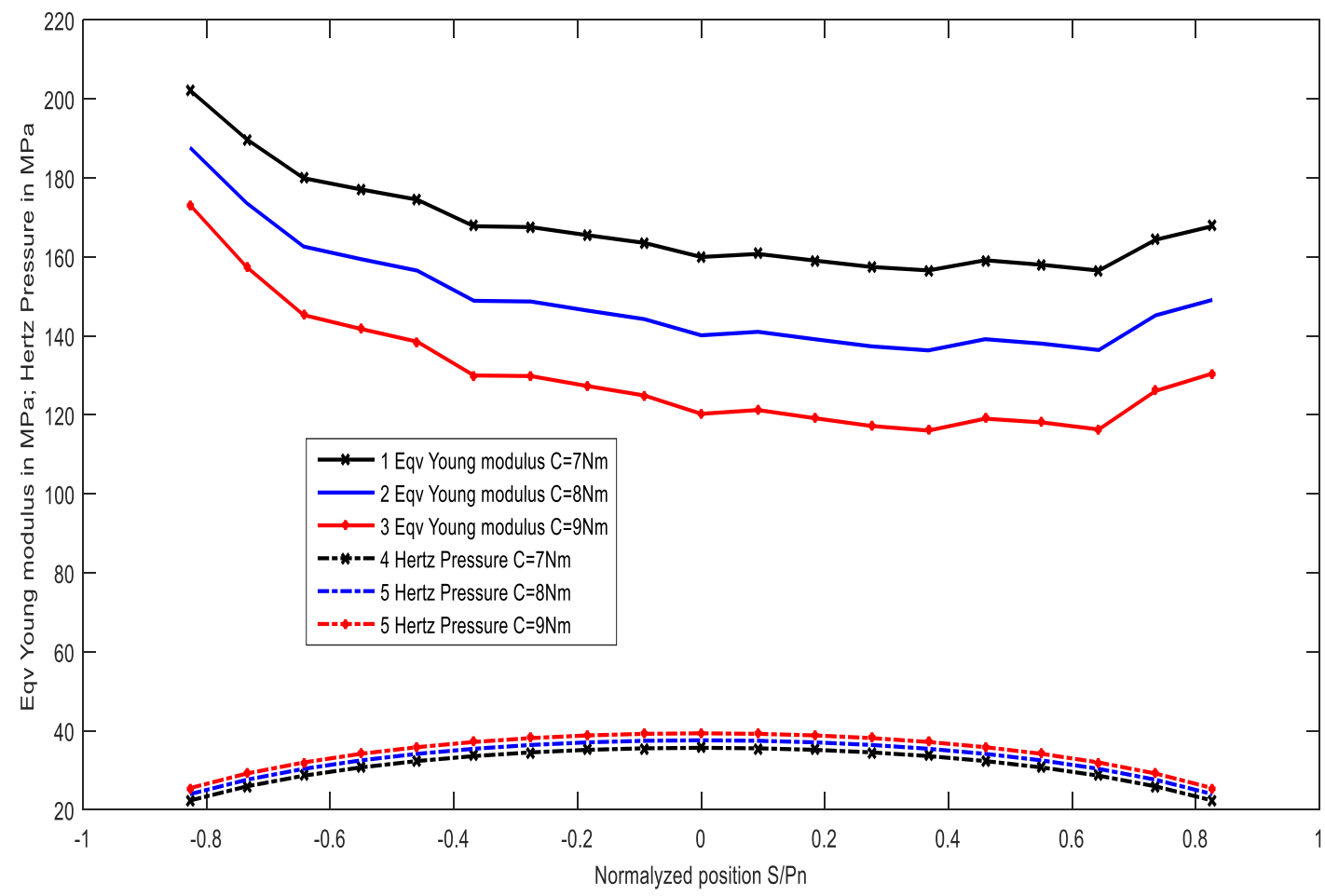

Figure11-a Variation of the pressure of Hertz P and of the Young equivalent modulus E according to the normalized position and according to the transmitted torque: $7 \mathrm{Nm}, 8 \mathrm{Nm}, 9 \mathrm{Nm}$. 


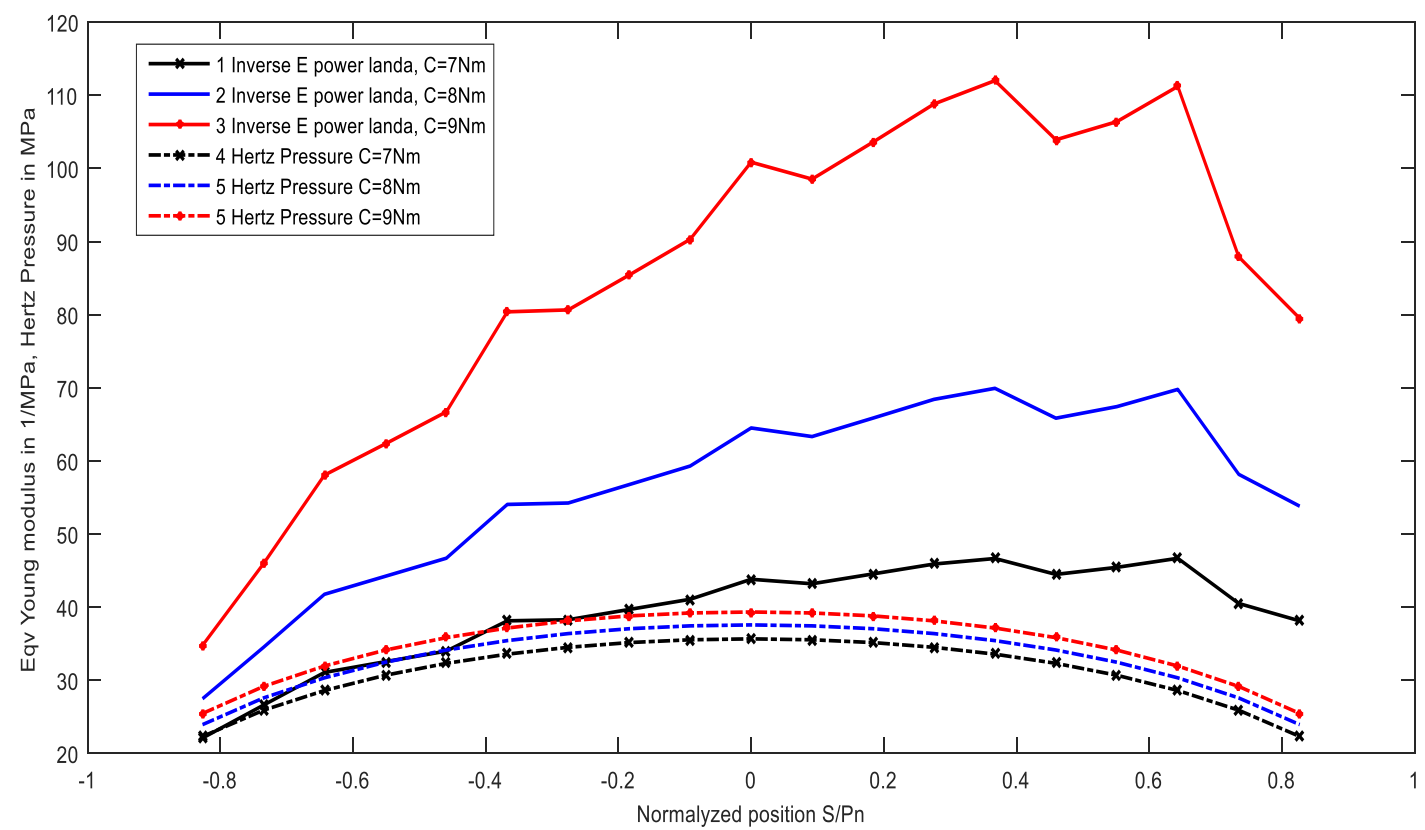

Figure11-b Variation in Hertz pressure P and compliance 1/E according to the normalized position and according to the transmitted torque: 7Nm, 8Nm, 9Nm.

\section{2- Results discussions}

As we mentioned in our methodology, the unknown parameters of our two studied models can be determined by calculation, except the wear coefficient ki and the exponential wear coefficient $\lambda$ which require determination by experimental method. Even the statistical regression method proposed for the approximate calculation of the wear coefficient ki, a priori requires the wear test in order to be able to measure the values of the roughness after profile wear, which will then be introduced into the calculation; which makes it a hybrid experimental-computation method in reality.

So in case study I for the acetal / acetal meshing, the experimental results of K. MAO [9] provide us with several operating conditions where the torques have been varied and all the other parameters are fixed.

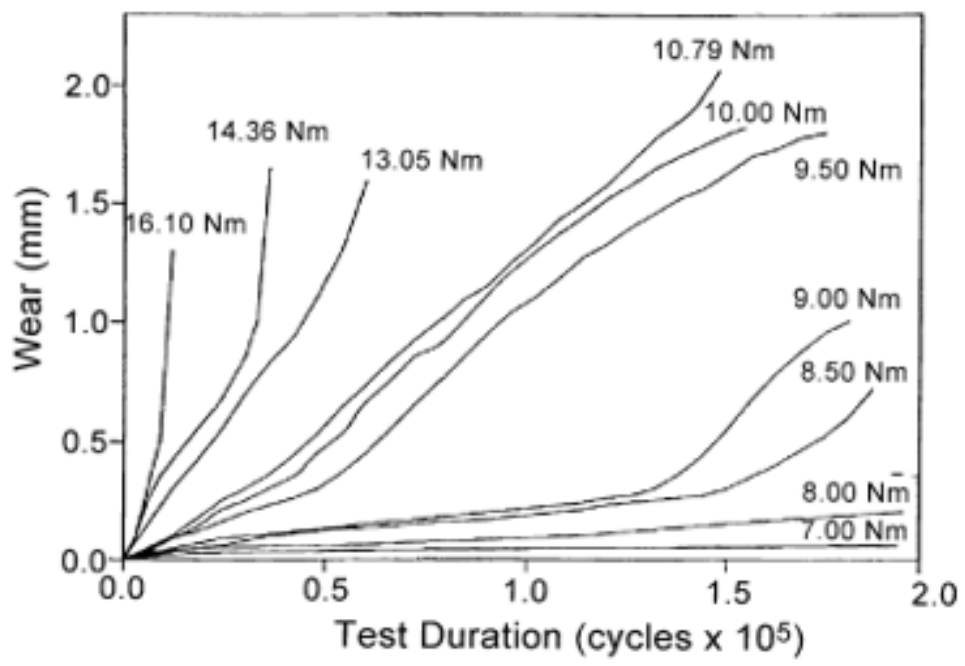

Figure 4- Wear tests at the pitch point of the acetal gears $(\omega=1000 \mathrm{rpm})$.

To make it easier to read, we recall Figure 4 of the results here and we can notice that the curves for the $7 \mathrm{Nm}, 8 \mathrm{Nm}, 8.5 \mathrm{Nm}$ and $9 \mathrm{Nm}$ torques clearly show the linearity that, an assumed constant wear rate throughout the cycle would give; that models also assume. We have therefore chosen the torque curve $\mathbf{8 N m}$ which is well representative for the determination of the wear coefficients $\mathrm{ki}$ and at the pitch point of the driving gear. The experimental curve gives us a wear rate of $9.3 \times 10^{-4} \mu \mathrm{m} /$ cycle. Using our Matlab program, by interactive method, we varied the value of $\lambda$ until we had the same model wear rate of $9.3 \times 10^{-4} \mu \mathrm{m} /$ cycle for the pitch point. So we got the value of $\boldsymbol{\lambda}=\mathbf{2 . 9 2 0 8 0 6}$. In our hypothesis to be able to replace the wear coefficient ki by the compliance $1 / \mathrm{E}$ affected by an exponential coefficient $\lambda$ 
(exponential wear coefficient), we plan to keep $\lambda$ constant for a given material and adjust its possible variability depending on the parameters by introducing correction factors into the model. For the time being, after having determined it for the pitch point, we have considered it constant for all the normalized positions to obtain the wear rates of all the points of the profile of the tooth. Thus we obtained the results of figure 7.c which gives a good conformity between the form of wear given by the model and that given by the experimental tests as show by Düzcükoğlu [11]. The results in Figure 7.c also show that the wear on the driving gear (curve 1) is more considerable than that on the driven gear (curve 3) on approach, but at recess the phenomenon is reversed for the two gears and this is normal. Thus the maximum wear rate on approach is $\mathbf{5 4 . 0 2 \times 1 0 ^ { - 4 }} \boldsymbol{\mu m} /$ cycle for the driving gear in the position $\mathbf{S p n}=\mathbf{- 0 . 5 5 1 2}$ and $\mathbf{3 1 . 9 9 \times 1 0 ^ { - 4 }} \boldsymbol{\mu m} / \mathbf{c y c l e}$ for the driven gear in the position $\mathbf{S p n}=\mathbf{- \mathbf { 0 . 3 6 7 4 }}$, but at recess, it is $\mathbf{4 4 . 0 5 \times 1 0 ^ { - 4 }} \boldsymbol{\mu m} /$ cycle for the driving gear at the position $\mathbf{S p n}=$ $\mathbf{0 . 5 5 1 2}$ and $\mathbf{8 9 . 7 1 \times 1 0 ^ { - 4 }} \boldsymbol{\mu m} /$ cycle for the driven gear at the position $\mathbf{S p n}=\mathbf{0 . 6 4 3 0}$.

As for the adapted Flodin model, we know that it is an already validated model, but its weakness remains the great variability of the wear coefficient ki and the need for its determination point by point for the profile of the tooth. In our present study, as we have only the experimental result of the pitch point, we used the formula of the statistical regressions of Janakiraman et al [17]. However, the values of the roughnesses $\mathrm{R} \alpha 1, \mathrm{R} \alpha 2$ introduced are assumed to be equal and constant over the entire profile of the tooth, and this common value is determined such that the model wear is equal to the experimental wear at the pitch point. Thus we have obtained table 3 which summarizes the variability of the wear coefficient ki according to the load and the speed, and function of the normalized position Spn. Curve 5 in Figure 7.b also shows graphically, the variation of the wear coefficient ki according to the normalized position Spn. Once the ki are determined, the adapted Flodin model is applied to give the results of Figure 7.c. (curves 2 and 4). Note that the results are similar to those of the new model, except that the adapted Flodin underestimated the wear rate on approach, compared to the new model and to Düzcükoğlu [11]. This is certainly due to the approach ki values that need to be adjusted. On the other hand, the two models are practically married during the recess phase. From the observation of the results from the two models, it is obvious that if the new model is validated, it brings notable advantages in its application for the prediction of the wear of plastic gears and their natural fiber composites exclusively, and for gears made of all materials in general. It therefore appears necessary to implement validation methods of the new model with a view to its application on an industrial scale. We therefore proposed a validation method which is described by Figures 8.a to d, and Table 2 which gave birth to the curve of the correction factor Kc in Figure 9. Table 2 and Figure 9 shows us that the value of Kc suddenly becomes high between the torques $9 \mathrm{Nm}$ and $9.5 \mathrm{Nm}$. This is due to the fact that one causes mild wear while the other causes moderate wear. This is why it would be necessary to consider separately the three types of wear (soft, medium and severe as shown by the tests of K. MAO) during the determination of the exponential coefficient of wear $\lambda$ and the factor of correction of the model. The examples of application of the validated model are shown in Figures 10.a and b. Although the mild and moderate wear cases are considered together, there is a good match between the results and this proves the good stability of this validation method.

When we analyzed all the parameters which can influence the value of the exponential coefficient of wear $\lambda$, we arrived at the conclusion that, vertically in terms of effect of (material, geometry, load, ..) and horizontally according to the normalized position in terms of the effect of (load, speed, coefficient of friction, specific slip, etc.), the combined effect is expressed on $\lambda$ in the form of the contact pressure $\mathrm{P}$ and the operating temperature $\mathrm{T}_{\mathrm{fo}}\left(\mathrm{E}=\mathrm{E}\left(\mathrm{T}_{\mathrm{fo}}\right)\right)$ of the operating point considered. The curves of figures 8-a to 8-d showed a superposition between the curves corrected by the coefficients $\lambda \mathrm{i}$ and the factors Kci (Table 2). The curves of figures 11-a and 11-b which show the variations according to the load and according to the normalized position Spn, of the pressure of Hertz $\mathrm{P}$, of the Young equivalent modulus $\mathrm{E}$ and of $1 / \mathrm{E}^{\lambda}$ explains this phenomenon by the fact that there is a translation transformation between the curves $\mathrm{Pi}$ as well as between the curves Ei, and a transformation of homothetic between the curves $1 / \mathrm{E}^{\lambda \mathrm{i}}$. We carried out many numerical simulations on the variation of the exponential coefficient $\lambda$ according to the normalized position Spn and we observed that $\lambda$ is practically constant according to Spn. In reality, the equivalent modulus already incorporates the variation effect according to Spn of the set $1 / \mathrm{E}^{\lambda}$. All this proves the great precision of the present validation method, which is confirmed by the application curves of Figures 10-a and 10-b.

\section{V- CONCLUSION}

This present study was able to lay the basis for predicting the wear of plastic gears and their composites. The models developed can already provide solutions to needs on an industrial scale. The new wear model that is being developed is also based on Archard's law, but compared to Flodin's model, it presents a simplicity in determining its exponential wear coefficient $\lambda$. The exponential wear coefficient $\lambda$ is more stable in the face of variations in operating parameters than the wear coefficient $\mathrm{k}$ of the Flodin model. As for the results, they effectively give the worn shape of the profiles in accordance with that obtained by the experimental tests of Düzcükoğlu [11]. 
[1] KOFFI D. Analyse des méthodes de dimensionnement des engrenages en plastique, Note de veille technologique réalisée pour CETIM (Senlis) - France, 2004

[2] Thaer OSMAN: Simulation de l'usure et d'avaries sur des dentures d'engrenages cylindriques - Influence sur le comportement statique et dynamique de transmissions par engrenages, Thèse de Doctorat, INSA de Lyon, 2012

[3] KOFFI. D., ETUDE DU COMPORTEMENT THERMIQUE DES ENGRENAGES CYLINDRIQUES DROITS EN PLASTIQUE, Thèse de Doctorat (Ph.D.) en Génie Mécanique, Ecole Polytechnique de Montréal, Mars 1987

[4] Anders Flodin, Wear Investigation of Spur Gear Teeth: Machine Elements, Department of Machine Design, Royal Institute of Technology, Sweden

[5] Jun ZHANG et Xianzeng, Effects of misalignment on surface wear of spur gears, ARCHIVE Proceedings of the Institution of Mechanical Engineers Part J Journal of Engineering Tribology 1994-1996 (vols 208-210). March 2015.

[6] Onishchenko, V.: Tooth wear modeling and prognostication parameters of engagement of spur gear power transmissions. Mechanism and Machine Theory, 2008, Vol. 43, p. 1639-1664.

[7] Wojnarowski, J., Onishchenko, V.: Tooth wear effects on spur gear dynamics. Mechanism and Machine Theory, 2003, Vol. 38, p. 161-178.

[8] Wu, S., Cheng, H.S. A Sliding wear model for partial EHD contact. Transactions of the ASME, 1991, Vol. 113, p. 134-141.

[9] K. Mao, A new approach for polymer composite gear design: Mechanical Engineering, School of Engineering and Design, Brunel University, Uxbridge, Middlesex UB8 3PH, UK, ELSEVIER, Wear 262 (2007) 432-441.

[10] K. Mao, W. Li, C.J. Hooke, D.Walton : Friction and wear behavior of acetal and nylon gears, ELSEVIER, Wear 267 (2009) $639-645$.

[11] DUZCUKOGLU H., Study on development of Polyamide gears for improvement of load carrying capacity, Tribology International, 2009, vol. 42, p. 1146-53.

[12] S.N. Kukureka, Y.K. Chen, C.J. Hooke, P. Liao: The wear mechanisms of acetal in unlubricated rolling-sliding contact, ELSEVIER, Wear 185 (1995) 18 .

[13] M. Kurokawa, Yoshitaka Uchiyama, Tomoaki Iwai, and Susumu Nagai: Performance of plastic gear made of carbon fiber reinforced polyamide 12. ELSEVIER, Wear. 254 January 2003, 468-473.

[14] Flodin, A., Andersson, S.: Simulation of mild wear in helical gears. Wear, 2000, Vol. 241, p. 123-128.

[15] Flodin, A., Andersson, S.: Simulation of mild wear in spur gears. Wear, 1997, Vol. 207, p. 16-23.

[16] N. AGBETOSSOU et al: NEW APPROACH BASED ON ANALYTIC-NUMERICAL METHOD FOR CALCULATING THE SLIDING DISTANCE OF TEETH PROFILE POINTS DURING GEARS MESHING. International Journal of Advanced Research, Vol 7, Issue 12, December 2019.

[17] Janakiraman V, Li S and Kahraman A.: An investigation of the impacts of contact parameters on wear coefficient. ASME J Tribol 2014; 136(3): 1-7.

[18] Jun ZHANG et Liu Xianzeng,: Effects of misalignment on surface wear of spur gears, ARCHIVE Proceedings of the Institution of Mechanical Engineers Part J Journal of Engineering Tribology 1994-1996 (vols 208-210). March 2015. 